\title{
Perceived Organizational Support and Workplace Incivility: The Mediating Role of Psychological Empowerment in Egyptian Organizations
}

\author{
Maha Misbah Shabana* \\ Lecturer of Business Administration, Faculty of Commerce, Damietta University, Egypt \\ E-mail:moha@du.edu.eg \\ Asmaa Azmy Abdel-Hamid Mohamed \\ Lecturer of Business Administration, The Higher Institute of Computer and Business Administration \\ Al-Zarqa - Damietta \\ E-mail: asma.azmi13@yahoo.com
}

\begin{abstract}
Purpose - This study investigates the effect of perceived organizational support on workplace incivility through mediating psychological empowerment.

Design/methodology/approach - Data were collected and analyzed using the Structural Equation Model (SEM) by applying to a random sample of 384 employees in governmental organizations with a response rate $64.32 \%$.

Findings - The results showed a significant negative effect of perceived organizational support on workplace incivility. Further analysis found that perceived organizational support has positive effect on psychological empowerment. In addition, psychological empowerment plays a critical role in maximizing the impact of perceived organizational support in buffering the negative effect of workplace incivility in Egyptian governmental organizations.

Practical implications - In the light of the findings, a number of practical recommendations were suggested to alleviate the negative effect of workplace incivility through developing a health-friendly and civil work environment that prevents the destructive influence of incivility behaviors at workplace.

Originality/value - This study adds to previous research by suggesting how organizations can benefit from positive practices in mitigating negative behaviors like work incivility.
\end{abstract}

Keywords: Workplace incivility; Perceived organizational support; Psychological empowerment.

DOI: $10.7176 / \mathrm{EJBM} / 13-24-03$

Publication date: December $31^{\text {st }} 2021$

\section{Introduction}

Social interactions at work play a crucial role in employees' well-being at workplace because any employee wants to be treated with respect and civility whether from his colleagues or his supervisors (Rukh et al., 2018). The highly competitive environment has a number of challenges to quality interpersonal relationships at workplace. Diversity at workplace requires more interaction with different social norms to retain a workforce capable of maintaining and improving the firm's competitive edge. Whereas, establishment of healthy relationships between employees and their co-workers, subordinates and supervisors have a positive effect on job satisfaction as well as productivity (Di Fabio and Duradoni, 2019).

Workplace Incivility (WI) refers to: "rude, discourteous, and unacceptable workplace behaviors that violate norms of mutual respect and civility such as exclusionary from meeting and decision making" (Selamat et al., 2019). WI may be low of intensity, but it is quite high in frequency at workplace and it has been correlated with greater psychological distress (Zia-ud-Din et al., 2017). Over the past ten years, research investigating WI has shown that it is a common issue in many organizations. There are many examples of WI behaviors such as disrespectful and condescending remarks, silent treatment, abandonment, unfriendly communication, inconsiderate behavior and hostile stares (Handoyo et al., 2018). WI has many definitions, but the common definition was used by Andersson and Pearson (1999) who define it as "low-intensity deviant behavior with ambiguous intent to harm the target, in violation of workplace norms for mutual respect. Uncivil behaviors are characteristically rude and discourteous displaying a lack of regard for others" (p. 457).

WI costs organizations many million dollars per year and causes many negative outcomes for employees such as negative emotions, increased work-family conflict, and counterproductive work behaviors, as well as negatively affecting employees' well-being satisfaction and intent to harm the target (Liu et al., 2018). WI can manifest itself in three ways. First, interpersonal incivility, where one person is directly uncivil toward another person at workplace. Second, cyber incivility, which refers to uncivil behavior among computer-mediated interactions through emails, texts, and social media communications. Finally, victimless incivility, which does not involve any harm impact for another person (Rukh et al., 2018; Torkelson et al., 2016). WI has many harmful results on both 
employees and organizations. Therefore, management should take this issue into its consideration to manage it effectively in the early stages before it escalates.

Perceived Organizational Support (POS) depends mainly on social exchange theory where each part must offer something of value to another part and each part must see exchange as reasonably fair (Kanwal et al., 2019). Accordingly, if employees perceive higher organizational support at workplace, their commitment toward organization will increase because of the positive impact of POS on organizational sustainability performance (Wange et al., 2018; Rukh et al., 2018). In addition, if the supervisor thinks and cares about his subordinates' needs, then these employees will also think and care about their organization. When employees receive support from their organization, POS generates a sense of commitment to repay in turn through having a behavior which helps in achieving the goals of organization. High POS increases employees' interest in their work and increases vitality at workplace (Hakeem and Nisa, 2016).

\section{Hypotheses Development}

\subsection{Perceived Organizational Support and psychological empowerment}

POS positively contributes to employees' emotional relations with their workplace. Moreover, it has a positive influence on both job satisfaction as well as organizational commitment. When employees have high level of POS, they are encouraged to meet organizational desired objectives with a high motivation. In addition, employees reciprocate high level of POS by showing more commitment and changing their intention to quit (Sen et al., 2021; Sharma and Biswakarma, 2020; Islam et al., 2013).

Moreover, employees are psychologically encouraged to exert more effort and time when they receive high level of POS because a good fit between employees' personal values and those of their organization encourages them to feel with greater meaningfulness and psychological safety (Biswas and Bhatnagar, 2013). Additionally, employees will feel more confident when they perceive organizational support. Consequently, this support enables them to develop their competence and impact at workplace, a sense of self-determination and meaning while performing their organizational tasks (Ahmed et al., 2010). According to the organization support theory, employees are more likely to develop more positive attitudes towards their organization if they perceive more support from it, then they will be motivated to perform well at work (Abdulrab et al., 2018). At the same time, Hashemi et al. (2012) concluded that the perception of organizational support leads to a significant variation of agricultural worker's perception interpretation of his PE. Furthermore, POS appears to have an important PE indicator. Accordingly, the first hypothesis can be formulated as the following:

\section{H.1: POS has a positive effect on PE.}

\subsection{Relationship between Perceived Organizational Support and Work Incivility}

Many previous studies found that employees reduce their workplace contribution when they face incivility at workplace because they want to feel respected and appreciated when dealing with others at work (Cragg and Joan, 2018). However, if the organization supports its employees, they will have a sense of appreciation and respect for their contribution, this feeling in return creates a respectful atmosphere and civility throughout the organization. Therefore, employees will have good interpersonal relations with their co-workers and subordinates. On the other hand, if the organization does not support its employees, they will be depressed, anxious and will have uncivil behavior with other co-workers and subordinates (Tran et al., 2018). A supportive organization increases the feelings of employees to be respected and appreciated in their workplace, motivating them to continue learning new skills and gaining new knowledge that increases vitality at workplace.

In addition, employees evaluate the organizational support they receive at workplace and react according to this level of support. Then, they engage in civil behaviors when they feel that their organization cares and pay more attention to them (Yekinni and Tamunoipiriala, 2019). Moreover, theorists of social exchange demonstrate that employees who receive more support from workplace may contribute significantly to organizational success and compensate their organization with higher work performance, but if they do not receive sufficient support, they are more likely to exhibit negative behaviors towards it. In the light of abovementioned literature, the second hypothesis is formulated as the following:

\section{H.2: POS has a negative effect on WI.}

\subsection{Relationship between psychological empowerment and work incivility}

In today's dynamic and turbulent environment, most of the human resource practices are more interested in employees' behavioral norms to maintain and improve the firm's competitive edge. Any organization can retain the well-being of human resources through maximizing their PE because it motivates them to feel their work characterized by meaning, impact and self- determination. On the other hand, WI plays obstructive role in gaining organizational goals because of its side effects on employees' motivations. Incivility may be a result of the global, technological and multicultural economy that we live and work. Many organizations have cultural diversity because of diversity in age, sex, nationality, and social status among employees. This diversity affects the quality 
of relationships between co-workers and supervisors. PE has a negative and significant effect on WI (Greenslade, 2021; Kanwal et al., 2018; Chiang and Hsieh, 2012).

According to the theory of social exchange, employees who receive more support from their organizations would be more likely to feel obligated to "repay" the organization's respect, appreciation and decrease incivility behaviors among their colleagues. Accordingly, employees who have receive more POS would be less likely to leave the organisation (Ugwu et al., 2018). PE results in a more civilized work environment as well as improved interpersonal skills by promoting many positive activities which include rejection to engage in an act of incivility, rudeness intolerance, and offenders apologizing to colleagues for the impolite behavior (Oyeleye et al., 2013). Because POS is an indicator of positive work behavior that results in a positive work environment. Then, when the employee feels the meaning of his work and self-determination, he will commit to decrease his incivility behaviors at workplace.

Danish (2019) has concluded that Individuals who experience incivility may also experience psychological distress. Because WI negatively affects mutual respect in the work and cooperation, PE can play a critical role in adopting civil behaviors at workplace and decreasing incivility behaviors. In their study on teachers' perceptions of PE in Turkey, Aksel et al. (2013) pointed out that PE is an effective approach to improve employees' attitudes and work related behaviors, and thus many authors showed that PE may increase an internal motivation of employees to decrease WI behaviors (Yilmaz and Toylan, 2021; Seibert et al., 2011; Gorji, and Ranjbar, 2013; Garg and Suri, 2013). Additionally, empowering human resources influence directly and indirectly on all organization factors especially the negative behaviors at workplace, namely incivility behaviors. Consequently, managers should introduce required support for developing empowerment by giving employees independence; freedom; feeling meaning and impact at work to reduce WI to a minimum level. Thus, empowerment of human resources offers opportunity for utilizing hidden capacities of human resources which are not fully utilized, because it disseminates positive behaviors among employees and decreases WI behaviors (Yilmaz and Toylan, 2021; Naderi and Hoveida, 2013).

Firozabad (2013) stated that the higher the PE the teachers feel in their work, the more satisfied with their work and the lower tendency they show to express WI because this makes employees adopt positive behaviors at workplace. Saufi et al. (2013) illustrated that when employees have high level of self-determination as well as freedom in work, they feel that their work has high meaning and impact, then they will behave altruistically and get excited to decrease WI behaviors. Iiu and Tsaur (2014) also have found that employees who have high level of PE (more self-determination, doing meaning tasks, being competent and having a profound effect on their work) are less likely to engage in WI. Consequently, the third hypothesis is:

\section{H. 3: PE has a negative impact on WI.}

\subsection{Mediating role of psychological empowerment}

Several previous studies have demonstrated that high level of POS of employees decreases the level of WI (Cragg and Joan, 2018; Chiang and Hsieh, 2012; Shen et al., 2013). Furthermore, achieving high level of PE requires more POS (He et al., 2020; Tran et al., 2018; Kanwal et al., 2019; Naderi and Hoveida, 2013; Malik et al., 2013; Gorji, and Ranjbar, 2013). However, there is still a lack of understanding about the mediating effect of PE between POS and WI. Consequently, this study investigates the nature of this mediating effect because the previous studies demonstrated that POS has a significant effect on PE and proposed that PE has an effect on WI. Therefore, the fourth hypothesis is:

H. 4. PE mediates the relationship between POS and WI.

Accordingly, the research model can be formulated as in figure 1 .

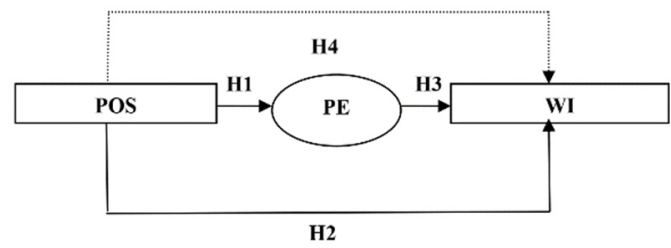

Fig. 1. Research Model.

Note:

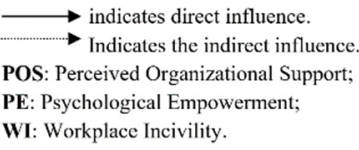

\section{Research Methodology and Measurement Development}

The relationships between POS, PE, and WI are examined from the viewpoint of employees in governmental organizations. WI is more likely to occur among public employees because of decreased autonomy due to a 
bureaucratized organizational culture that decreases employees' job motivation and morale and cause them to display counterproductive work behaviors. A random sample was used to collect data from 5 service directorates of Dakahlya governorate through the questionnaire method.

A Likert scale was used to measure the variables and includes 5 points that range from one (strongly disagree) to five (strongly agree). POS was measured through 10-items depending on Rhoades et al. (2001) (such as "My organization strongly considers my goals and values"). Meanwhile, PE was adopted from Spreitzer (1995) which includes a 12-item scale (such as "I have considerable opportunity for independence and freedom in how I do my job").

Lastly, WI was adopted depending on Leiter et al. (2011) to assess the recurrence with which an employee has experienced incivility in workplace such as rudeness or disrespectful remarks from supervisors or colleagues in the previous month. A typical component of peer rudeness is "Ignored you or showed disrespect for your opinion". The questionnaire has been validated then data were collected and analyzed.

\subsection{Sample Characteristics}

Using questionnaire, data were randomly collected from public employees from March to May 2021. 400 questionnaires were distributed. The number of valid ones was 247 with $61.75 \%$ response rate. As displayed in Table 1, the majority of them were male respondents $(70.85 \%)$, aged between 45 and less than 55 years $(37.25 \%)$, and most of them have a bachelor degree (48.58\%). All respondents had previous experience of more than five years and were distributed across all managerial levels of the organization.

Table 1. Respondents' characteristics.

\begin{tabular}{|l|c|c|c|c|c||}
\hline \multicolumn{1}{|c|}{ characteristics } & $\begin{array}{c}\text { Sample } \\
(\mathrm{N}=247)\end{array}$ & $(\mathbf{\%})$ & characteristics & $\begin{array}{c}\text { Sample } \\
(\mathrm{N}=247)\end{array}$ & $(\mathbf{\%})$ \\
\hline Gender: & $\mathbf{2 4 7}$ & $\mathbf{1 0 0}$ & Education: & $\mathbf{2 4 7}$ & $\mathbf{1 0 0}$ \\
Male & 175 & 70.85 & Deplume & 85 & 34.41 \\
Female & 72 & 29.15 & Bachelor & 120 & 48.58 \\
& & & Post Graduate & 42 & 17.01 \\
\hline Age: & $\mathbf{2 4 7}$ & $\mathbf{1 0 0}$ & Experience: & $\mathbf{2 4 7}$ & $\mathbf{1 0 0}$ \\
25- less than 35 years & 60 & 24.29 & 5- less than 10 years & 65 & 26.32 \\
35- less than 45 years & 75 & 30.36 & 10- less than 20 years & 87 & 35.22 \\
45- less than 55 years & 92 & 37.25 & 20- less than 30 years & 70 & 28.34 \\
55 years and more & 20 & 8.10 & 30 years and more & 25 & 10.12 \\
\hline Managerial Levels: & $\mathbf{2 4 7}$ & $\mathbf{1 0 0}$ & & & \\
Top management Middle & 115 & 46.55 & & & \\
management & 132 & 53.45 & & & \\
\hline \hline
\end{tabular}

\subsection{Descriptive Analysis}

According to table 2, the employees perceived a moderate level of POS and caring about their welfare (mean= 2.85). In contrast, they had lower level of conformity with PE (Mean=2.76). The WI level was high $(\mathrm{Mean}=4.10)$, which indicates that employees adopt many incivility behaviors at workplace because of lower POS. Therefore, they hesitate to aid their new colleagues and adapt them to the working environment, as well as willingness to perform their peers' tasks when they are absent. As table 2 demonstrates Cronbach's alpha values ranging between 0.85 and 0.94 and this indicates a good reliability.

Table 2. Descriptive analysis.

\begin{tabular}{|c||c||c||c|c|c||}
\hline \multirow{2}{*}{ Variables } & \multicolumn{1}{|c||}{$\begin{array}{c}\text { Mean (S.D.) } \\
(\mathrm{N}=247)\end{array}$} & $\begin{array}{c}\text { Cronbach's } \\
(\alpha)\end{array}$ & 1 & 2 & 3 \\
\hline \hline 1. POS & $2.85(1.35)$ & 0.86 & $\mathbf{0 . 7 2}$ & & $\mathbf{0 . 6 3}$ \\
\hline 2. PE & $2.76(1.27)$ & 0.85 & $0.68^{* *}$ & $\mathbf{0 3}$ & \\
\hline 3. WI & $4.10(0.86)$ & 0.94 & $-0.56^{*}$ & $-0.42^{* *}$ & $\mathbf{0 . 8 7}$ \\
\hline
\end{tabular}

Note: Diagonal values depict the square root of the Average Variance Extracted.

$$
* p<0.05 ; * * p<0.01 \text {. }
$$

\subsection{Validity and Reliability}

Confirmatory factor analysis (CFA) has been utilized in order to test the validity of the variables. In the testing model of CFA, the adaptability scores were $\chi^{2}=1640.36 ; \mathrm{df}=346 ; \chi^{2} / \mathrm{df}=4.74 ; \mathrm{RMSEA}=0.15 ; \mathrm{NFI}=0.85$; $\mathrm{NNFI}=0.86$ and $\mathrm{CFI}=0.8$. These scores are not satisfactory based on the standards of fitness indicated by Hair et al. (2006) $\left[\chi^{2} / \mathrm{df}<3, \mathrm{RMSEA} \leq 0.08, \mathrm{NFI} \geq 0.90, \mathrm{NNFI} \geq 0.90, \mathrm{CFI} \geq 0.90\right]$. Therefore, some modifications were made via deleting items with factor loading $<0.50$ as well as cross loadings (Bagozzi and Yi, 1988). The modifications in the testing model demonstrated acceptable indices: $\chi^{2}=978.67 ; \chi^{2} / \mathrm{df}=2.83 ; \mathrm{RMSEA}=0.05 ; \mathrm{CFI}=0.95 ; \mathrm{NNFI}=$ 
0.92 ; and NFI $=0.91$. The composite Reliability $(\mathrm{CR})$ varied from $0.85-0.94$ as compared to the criterion (0.6). All factors had high average variance extracted (AVE) ranging between 0.63 and 0.87 as compared to the criterion (0.50). In addition, the determination coefficient $\left(\mathrm{R}^{2}\right)$ of any two variables was less than the AVE, then the scale was acceptable and valid (Fornell and Larcker, 1981).

\subsection{Structural Equation Model (SEM)}

The results of the Structural equation model (SEM) showed the $\chi^{2}\left(\Delta \chi^{2}\right)$ difference between the direct effect model as well as the full mediation model was 42.85 as appeared in table 3. According to the indices CFI, GFI, RMSEA as well as NNFI, full mediation model had better fitness than the direct effect model. Then, the difference between the model of partial mediation and the model of full mediation $\left(\Delta \chi^{2}\right)$ of $\chi^{2}$ is 17.03 . Therefore, the model of partial mediation is better than the model of full mediation, in which indicators of fitness are $\chi^{2} / \mathrm{df}=2.91$; GFI $=0.92$; $\mathrm{CFI}=0.94 ; \mathrm{NNI}=0.93$ and $\mathrm{RMSEA}=0.04$. subsequently, the model of partial mediation fitness is considered favorable.

Table 3. Fit indices of structural models

\begin{tabular}{||l||c|c|c|c||c||c||c||}
\hline \multicolumn{1}{|c||}{ Model type } & $\chi^{\mathbf{2}}$ & $\begin{array}{c}\boldsymbol{\chi}^{\mathbf{2}} / \mathbf{d f} \\
(<\mathbf{3})\end{array}$ & $\Delta \chi^{\mathbf{2}}$ & $\begin{array}{c}\text { GFI } \\
(>\mathbf{0 . 9 0})\end{array}$ & $\begin{array}{c}\text { CFI } \\
(>\mathbf{0 . 9 0})\end{array}$ & $\begin{array}{c}\text { NNFI } \\
(>\mathbf{0 . 9 0})\end{array}$ & $\begin{array}{c}\text { RMSEA } \\
(<\mathbf{0 . 0 8})\end{array}$ \\
\hline \hline Direct Effects Model & $\begin{array}{c}1067.04^{*} \\
(\mathrm{df}=247)\end{array}$ & 4.32 & - & 0.83 & 0.92 & 0.90 & 0.07 \\
\hline Full Mediation Model & $\begin{array}{c}778.50^{* *} \\
(\mathrm{df}=247)\end{array}$ & 3.15 & 288.54 & 0.91 & 0.92 & 0.91 & 0.06 \\
\hline Partial Mediation Model & $\begin{array}{c}716.47^{* *} \\
(\mathrm{df}=247)\end{array}$ & 2.90 & 62.03 & 0.92 & 0.94 & 0.93 & 0.04 \\
\hline
\end{tabular}

Note: $\Delta \chi^{2}$ indicates the difference between each two models respectively.

${ }^{*} \mathrm{p}<0.05 ;{ }^{* *} \mathrm{p}<0.01$.

According to table 3, the partial mediation model was favourable as compared to both the model of direct effect and the model of full mediation. According to the model of partial mediation in table 4, POS of employees has a positive effect on their PE $(\beta=0.38, \mathrm{p}<0.01)$. Consequently, this result supports H.1. In addition, POS has a negative effect on WI $(\beta=-0.21, \mathrm{p}<0.05)$. Therefore, this result validates H.2. In addition, PE has a negative effect on WI $(\beta=-0.24, p<0.001)$, and this finding proves and supports H.3.

Table 4. Measuring the mediating role of PE

\begin{tabular}{|c|c|c|c|}
\hline \multirow[b]{2}{*}{ Model } & \multicolumn{3}{|c|}{ Standardized path coefficients ( $t$-value) } \\
\hline & $\begin{array}{c}\text { Direct Effects } \\
\text { Model }\end{array}$ & $\begin{array}{c}\text { Full Mediation } \\
\text { Model }\end{array}$ & $\begin{array}{c}\text { Partial Mediation } \\
\text { Model }\end{array}$ \\
\hline $\mathrm{POS} \rightarrow \mathrm{WI}$ & $-0.27\left(15.46^{* * *}\right)$ & & $-0.21\left(6.26^{*}\right)$ \\
\hline $\mathrm{POS} \rightarrow \mathrm{PE}$ & & $0.32\left(12.16^{* * *}\right)$ & $0.38\left(10.51^{* *}\right)$ \\
\hline $\mathrm{PE} \rightarrow \mathrm{WI}$ & & $-0.26\left(11.57^{* * *}\right)$ & $-0.24\left(6.05^{* * *}\right)$ \\
\hline
\end{tabular}

According to direct model in table 4, POS has a negative path coefficient on WI of employee (POS $\rightarrow$ WI: $\beta=$ $-0.27, \mathrm{p}<0.001)$. This means that the higher level of POS employees they have, the lower negative effect on their WI. In the same vein, POS has a positive effect on PE of employees (POS $\rightarrow P E: \beta=0.32, p<0.001$ ) according to full mediation model. This means that the higher level of POS employees they have, the higher positive effect on their PE. Additionally, PE has a significant negative effect on WI (PE $\rightarrow$ WI: $\beta=-0.26, p<0.001)$ this means that the higher level of PE employees they have, the lower negative effect on their WI.

Lastly, based on the model of partial mediation in table 4, POS of employees has a negative effect on WI ( $\beta=$ $-0.21, p<0.05)$. To determine the mediating effect of PE in the relationship between POS and WI, we multiply the two paths of $(\mathrm{POS} \rightarrow \mathrm{PE})$ and $(\mathrm{PE} \rightarrow \mathrm{WI})$. The results refer to POS and PE together negatively influenced on employees' WI $(\mathrm{POS} \rightarrow \mathrm{PE}) \times(\mathrm{PE} \rightarrow \mathrm{WI})=0.38 \times-0.24=-0.09)$. Consequently, this means that $\mathrm{PE}$ decreases the negative effect of WI from -0.21 to -0.09 because of the presence of PE as a mediator in this relationship. Therefore, this study found that PE buffers the negative effect of WI at workplace and plays a partial mediator in this relationship. This result supports H.4. figure 2 illustrates the results of testing hypotheses. 


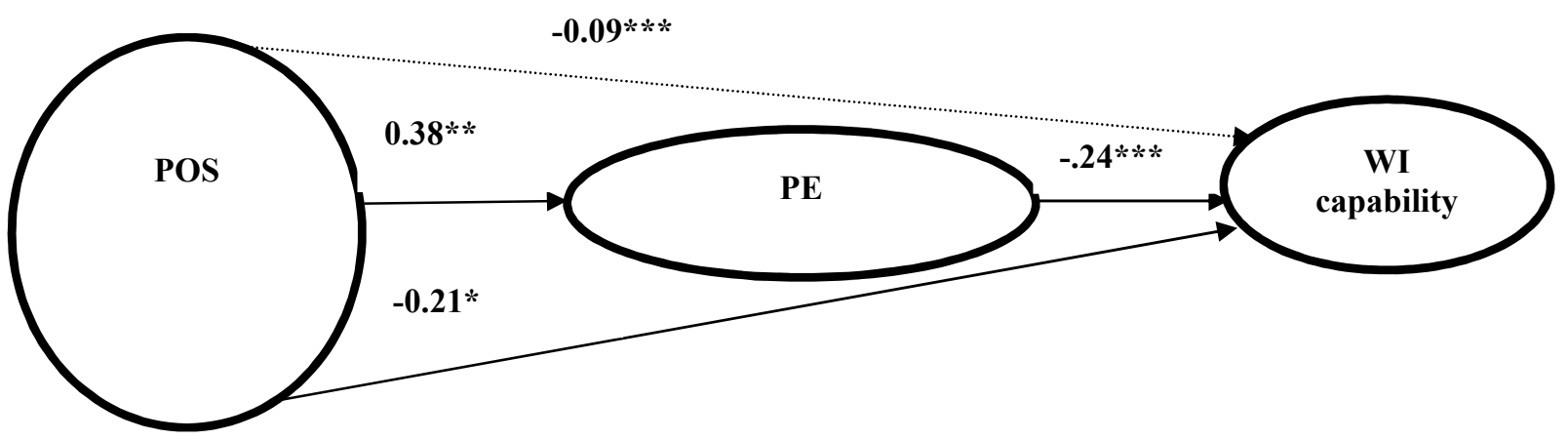

Fig.2 Hypotheses' testing results

\section{Discussion}

\subsection{Employees' Perceptions of POS, PE and WI}

Public employees have a modest level of POS $(\mathrm{M}=2.85 ; \mathrm{S} \mathrm{D}=1.35)$. Because lack of POS introduced by service directorates for their employees, the employees decrease their efforts and contributions to improve the image of studied service directorates among its clients. Additionally, studied service directorates do not appreciate their contribution to improve its well-being. This finding is consistent with the findings of the previous studies which demonstrated that people are psychologically motivated to exert high level of effort if they receive high level of POS. This leads to positive reactions such as increased workplace civility and decreased turnover intention and WI among employees (Zhang et al., 2021; Maan et al., 2020; Nitzsche et al., 2018; Shen et al., 2013; Epitropaki and Martin, 2013; Islam et al., 2013).

In addition, employees did not feel psychologically empowered by their service directorates in fulfilling their tasks, where $\mathrm{PE}$ was poor $(\mathrm{M}=2.76 ; \mathrm{SD}=1.27)$. Employees perceive that their jobs are no longer important to them, their tasks are not meaningful and they are not self-assured about their abilities to carry out their work activities. This result did not support the findings of Chiang and Hsieh's study (2012) of employees in hotels, where Taiwan hotel staff members' PE was slightly high.

On the other hand, employees have a high level of WI $(\mathrm{M}=4.10 ; \mathrm{SD}=0.86)$. Therefore, the lower the POS and PE of employees the higher WI of them. Most of employees have insufficient support from their organization due to the bureaucratic nature of their work and the centrality of decision making. This makes them feel meaningless in their work and that their jobs do not provide them with self-determination, competence and impact.

\subsection{The relationship between $P O S$ and $P E$}

The present study demonstrates that POS of employees is characterized by a significant positive influence on PE (H.1). This indicates that employees with high level of POS achieve high levels of PE and they perceive their work as significantly important and meaningful to them (meaning). In addition, they become more confident in their potentials and have the skills necessary to carry out their tasks efficiently (competence). Moreover, they have a chance to be independent in the way they perform tasks (Self-determination) and they have a significant effect on what occurs in their departments (impact). Akhtar et al. (2017) concluded that employees who experienced high levels of POS from their organization are more psychologically empowered than counterparts who had low POS. A high level of POS reinforces harmony between employees and their organization, making them feel with high meaningfulness and PE and they feel psychologically obliged to exert high level of effort and time to improve the image of their organization because they would be more convinced that they have required resources enabling them to effectively perform their tasks and they will reward for their efforts. Consequently, this support will motivate them to develop their competence, feel their impact at workplace and they feel with more selfdetermination while performing their organizational task and they will have positive emotions that motivate them to adopt civilized behaviors at workplace (Ko et al., 2021; Ahmed et al., 2010; Biswas and Bhatnagar, 2013).

According to assumptions of Social Exchange Theory which advocate that employee would view organizations to be supportive towards him, when the organizations provide sufficient social and organizational support and introduce adequate facility in the workplace to carry out job duties. This result is also consistent with those of many previous studies which demonstrated that high level of POS creates high level of PE (Sumathi, 2018; Lau, 2010). On the other hand, Hashemi et al. (2012) indicated that POS may be a strong predictor of PE and contribute several interpretations of the perception of agricultural workers of their PE. These findings align with those obtained by Spreitzer (2008) who asserted that employees feel more empowered when they realize that their leaders are trustworthy. The findings also align with those of Thomas and Velthouse's (1990) that psychological perspective regarding empowerment indicates that organizational environment may have a profound impact on employees' empowerment. Lastly, relationship between POS and PE in the present study is also compatible with the findings of Steinberg (2012) who showed that supervisor support was one of the strong predictors of PE among 
nurse aides in nursing homes.

\subsection{Relationship between POS and WI}

Employees with high levels of POS display decreased levels of WI. Consequently, POS negatively influences WI. This result supports H.2. Employees with a high level of organizational support, change their attitudes towards their organization and make it more positive, they have a great tendency to spend more effort and time to improve their organization's image from the perspective of its clients and they are hesitating to abuse the rights of others or show genuine concern and courtesy towards their co-workers; keeping abreast of changes and actively participate in building a positive image of their organization; always focus on what's right, rather than the negative side or rarely find mistake with what their organization is doing; and lastly, they feel that they are following a civil and respectful behaviors whether with their co-workers; supervisors or subordinates.

This result aligns with the model of Risk Management, in which WI is perceived as a threat to social identity, and thus leads to negative influence and disruption of recovery and stress (Jiménez and Kallus, 2010). Accordingly, when an employee receives a minimum level of POS, he follows negative behavior to keep his balance in organization, then many types of incivility at workplace whether verbal abuse like gossiping, rumours and rudeness; or nonverbal mistreatment like excluding his peers and ignoring them. This result also aligns with Miner et al. (2012) who reported that emotional and psychological support (indicated by a peer or colleague) and organizational support plays an important role in buffering the negative effect of WI and promoting positive and respectful behaviors among employees at workplace.

In addition, the findings of this study are compatible with those of prior studies which demonstrated that when employees perceive increased POS, they are more likely to demonstrate low WI. At the same time, the incivility of co-workers had a significant relation with the incivility of supervisor; nonetheless, it demonstrated only marked influence on work-associated recovery (Rani et al., 2021; Ko et al., 2021; Jiménez et al., 2015). In addition, because of incivility can be considered as a mild form of deviant behavior in which the intention to harm is less apparent, when employee perceives high level of PE from his supervisors or organization, he will decrease his negative behaviors with co-workers and supervisors, then WI will decrease.

\subsection{Relationship between PE and WI}

The results demonstrated that PE has a negative influence on WI (H.3), which indicates that employees with high level of PE are not likely to engage in incivility behaviors at workplace. We can explain this result in the light of social exchange theory where employees do not engage in any uncivil behaviors that may cause harmful effect on their co-workers, supervisors, or subordinates only when they feel with high levels of PE due to the meaning of their work, they have the right to initiate and adjust actions, and lastly they have an impact on major work outcomes. Therefore, Rukh et al. (2018) recommended that organizations should provide environment in which employees perceive support from organization and fair reward, and feel respectable at workplace.

Therefore, employees with high level of PE are prepared to put more effort and time into their work and try to find out better ways to collaborate with their co-workers to do their jobs effectively and help them to overcome problems. They contribute to the achievement of their organization's goals, comply with regulations, adapt to undesired circumstances without complaining, and avoid making problems with their colleagues. This finding aligns with prior studies which highlighted the contribution of $\mathrm{PE}$ in motivating positive behaviors and decreasing WI (Elziny and Mohamed, 2021; Maan et al., 2020; Ojo and Tamunoipiriala, 2019; Liu et al., 2018; Chiang and Hsieh, 2012; Naderi and Hoveida, 2013; Spreitzer, 2008; Malik et al., 2013; Aksel et al., 2013; Gorji, and Ranjbar, 2013).

\subsection{The mediating effect of PE between POS and WI}

PE plays a partial mediator between POS and WI (H.4), in which POS of employees has a direct negative influence directly on WI $(\beta=-0.27, p<0.05)$. At the same time, POS indirectly affected WI through PE $(0.38 \times-0.24=-0.09)$. Findings revealing PE has a negative on WI, and this result is compatible with prior studies that investigated POS, PE and WI (Sen et al., 2021; Potipiroon and Ford, 2019; Liu et al., 2018; Chiang and Hsieh, 2012; Naderi and Hoveida, 2013; Spreitzer,2008; Malik et al., 2013; Aksel et al., 2013; Gorji, and Ranjbar, 2013). Hence, POS decreases the level of WI in service directorates through PE. Therefore, managers should pay more attention and care to create a healthy working environment for employees and ensure that incivility behaviors are kept to a minimum level.

This result agrees with many previous studies concluding that POS play a critical role in buffering the negative effect of WI behaviors (Potipiroon and Ford, 2019; Rayan et al., 2018). This result is compatible with Hashemi et al. (2012) on the mediator role of PE, which demonstrated that employees with high level of POS display high levels of PE and are ready to adopt proactive behavior that respect co-workers and supervisors at workplace. Based on the Conservation Of Resources theory (COR), when an employee fails to gain resources (POS), he will try to cope with that negative action with more stressful behaviors and then concerned with incivility behaviors (Huner, 
2019). Thus, to decrease level of WI, organization must value any extra effort from employees and introduce enough support to them, as this will motivate employees to exhibit high level of PE to reduce the level of WI and encourage them to collaborate with their colleagues more effectively and civility. Therefore, employees with high level of PE are encouraged to display more civil behaviors among their colleagues, supervisors, and subordinates.

\section{Conclusion and Managerial Implications}

\subsection{Conclusion}

PE plays a partial mediating role in the relationship between POS and WI. In addition, PE buffers the negative effect of WI when it is introduced in this relationship. Additionally, POS positively influenced PE and negative affected WI, whereas PE of employees negatively influenced WI. All these results support the hypotheses.

\subsection{Managerial Implications}

Due to the negative effect of WI at workplace, managers have to encourage new suggestions as well as ideas from employees to redesign job tasks to be more meaningful and competent. When employees feel that they have an impact in their jobs and departments; they will have high level of PE. Therefore, managers must grant employees real power and impact to be proactive in solving clients and colleagues' problems promptly. To minimize side effects of WI, managers must follow civil behaviors to create healthy work environments and be aware that their actions can have a cascading negative effect when observed by their subordinates.

Moreover, managers should provide necessary support for the development of PE through employees' sense of competence through increasing employees' belief that their abilities are enough to perform tasks with their existing skills, where PE provides employees with potential capacities for utilizing their abilities and creates positive behaviors among them (Beheshtifar and Herat, 2013; Naderi and Hoveida, 2013). Accordingly, managers can utilize PE as a tool to maximize the impact of POS to keep WI to a minimum, especially in Muslim communities with a high level of $\mathrm{PE}$, which discard rudeness among its citizens. Consequently, managers should endeavour to establish organisational systems and develop a health-friendly, civil work environment that prevents the destructive influence of incivility behaviors at workplace and subsequently enhances polices that support the welfare and interest of their employees.

\subsection{Research limitations and Future Research Suggestions}

There are many limitations to the current study that should be noted to provide opportunities for further research. First, this study was applied on employees at five services directorates in dakahlia governorate as a research subject. Thus, the results can only be applied to these employees and cannot be extended to other services directorates in dakahlia or another governorate in Egypt. So, it is suggested to examine the level of PE in the rest of other services directorates in dakahlia and other governorates in Egypt to examine its influence on the relationship between POS and WI. Second, this study examined the variables as a total construct, so we need to examine interactive relationships between the sub-dimensions of each variable and the dimensions of other variables. Finally, this study focused on WI as dependent variable and PE as the mediator, but the results would change if we used WI as an independent variable, POS as the moderator and PE as the dependent variable.

\section{References}

Abdulrab, M.; Zumrah, A.R.; Almaamari, Q.; Al-Tahitah, A.N.; Isaac, O. and Ameen, A. (2018), "The Role of Psychological Empowerment as a Mediating Variable between Perceived Organizational Support and Organizational Citizenship Behaviour in Malaysian Higher Education Institutions", International Journal of Management and Human Science, Vol.2 No.3, pp.1-14.

Ahmed, A., Muhammad, Ur- Rehman, Inam, Ul Haq, Ahmed, J.F., Bilal, G.M. and Umer, A.M. (2010), "Perceived Organizational Support and Psychological Empowerment”, European Journal of Social Sciences, Vol.17 No.2, p. 186.

Akhtar, S.; Luqman, R.; Raza, F.; Riaz, H.; Tufail, H.S. and Shahid, J. (2017), "The Impact of Workplace Incivility on the Psychological Wellbeing of Employees through Emotional Exhaustion", European Online Journal of Natural and Social Sciences, Vol.6 No.3, pp. 492-507.

Aksel, I., Serinkan, C. Kiziloglu, M. and Aksoy, B. (2013), "Assessment of Teachers' Perceptions of Organizational Citizenship Behaviors and Psychological Empowerment: An Empirical Analysis in Turkey", Procedia-Social and Behavioral Sciences, Vol.89, pp. $69-73$.

Andersson, L. M., and Pearson, C. M. (1999), "Tit for Tat? The Spiraling Effect of Incivility in the Workplace”, Academy of Management Review, Vol.24, pp. 452-471.

Bagozzi, R., Yi, Y. (1988), "On the evaluation of structural equation models", Journal of the Academy of Marketing Science, Vol.16 No.1, pp. 74- 94.

Baron, R.M., Kenny, D.A., (1986), “The moderator-mediator variable distinction in social psychological research: conceptual, strategic and statistical considerations", Journal of Personality and Social Psychology, Vol.51, 
pp. 1173- 1182 .

Beheshtifar, M. and Herat, B.H. (2013), "To Promote Employees Commitment via Perceived Organizational Support", International Journal of Academic Research in Business and Social Sciences, Vol.3 Vol.1, pp. 306313.

Biswas, S. and Bhatnagar, J. (2013), "Mediator Analysis of Employee Engagement: Role of Perceived Organizational Support; P-O Fit; Organizational Commitment and Job Satisfaction”, VIKALPA, Vol.38 No.1, pp. $27-40$.

Chiang, C. F. and Hsieh, T.S. (2012), "The impacts of perceived organizational support and psychological empowerment on job performance: The mediating effects of organizational citizenship behavior", International Journal of Hospitality Management, 31, 180- 190.

Cragg, C.A. and Joan, F.E. (2018), "Empowering Employees to Reduce Perceptions of Workplace Empowering Employees to Reduce Perceptions of Workplace Incivility", Electronic Thesis and Dissertation Repositor y. 5490. https://ir.lib.uwo.ca/etd/5490.

Di Fabio, A. and Duradoni, M. (2019), "Fighting Incivility in the Workplace for Women and for All Workers: The Challenge of Primary Prevention”, Frontiers in Psychology, Vol.10, Article 1805, pp. 1-4.

Elziny, M.N. and Mohamed, H.E. (2021), "The Interactive Impact of Organizational Support, Service Training and Empowerment on Employees' Affective Commitment and Service Recovery Performance: Hotel Front Office Department's Perspective", Mohammed N. Elziny and Hany E. Mohamed, (JAAUTH), Vol.20 No.3, pp. 148-172.

Epitropaki, O. and Martin, R. (2013), "Transformational-transactional leadership and upward influence: The role of Relative Leader-Member Exchanges (RLMX) and Perceived Organizational Support (POS)", The Leadership Quarterly, Vol.24, pp. 299-315.

Fornell, C. and Larcker, D.F. (1981), "Evaluating structural equation models with unobservable variables and measurement error", Journal of Marketing Research, Vol.18 No.1, 39-50.

Gorji, M.B. and Ranjbar, M. (2013), "Relationship Between Psychological Empowerment of Employees and Organizational Citizenship Behavior”, Australian Journal of Basic and Applied Sciences, Vol.7 No.1, pp. 6775.

Greenslade, J. (2021), "The Spiralling Effects of Witnessing Incivility in the Workplace”, Dissertation submitted in partial fulfilment of the requirements for the Degree of Master of Science in Applied Psychology, University of Canterbury, Department of Psychology.

Hair Jr., J.F., Black, W.C., Babin, B.J., Anderson, R.E., Tatham, R.L. (2006), “Multivariate Data Analysis", $6^{\text {th }}$ ed. Prentice Hall, Upper Saddle River, NJ.

Hakeem, I.A. and Nisa, N.U. (2016), "Perceived organizational support: a review on its antecedents and outcomes", Abhinav International Monthly Refereed Journal of Research in Management and Technology, Vol.5 No.6, pp. 30-38.

Handoyo, S.; Samian; Syarifah, D. and Suhariadi, F. (2018), "The measurement of workplace incivility in Indonesia: evidence and construct validity", Psychology Research and Behavior Management, Vol.11, pp. 217-226.

Hashemi, S.M.K., Nadi, H.K., Hosseini, S.M. and Rezvanfar, A. (2012), “Agricultural Personnel's Proactive Behavior: Effects of Self efficacy Perceptions and Perceived Organizational Support", International Business and Management, Vol.4 No.1, pp. 83-91.

He, Y. Walker, J.M.; Payne, S.C. and Miner, K.N. (2020), "Explaining the negative impact of workplace incivility on work and non - work outcomes: The roles of negative rumination and organizational support", Wiley, DOI: $10.1002 / \mathrm{smi} .2988$

Huner, B.B. (2019), "Customer incivility and turnover intention of bank employees: the moderating role of perceived organizational support and big five personality traits", Master thesis in Business Administration, Middle east technical University.

Islam, T., Khan, S.R., Nourulkamar Bt, O., Ahmad, U., Ali, G., Ahmed, I. and Bowra, Z.A. (2013), "Turnover intentions: the influence of perceived organizational support and organizational commitment", Procedia Social and Behavioral Sciences, Vol.103, pp. 1238- 1242.

Jiménez, P., and Kallus, W. (2010), "Analysis of Resources and Strain at Work. The Recovery-StressQuestionnaire for Work (RESTQ-Work). Versions for Screening”, Organizational and Individual RecoveryStrain-Analysis. Poster Presented at 27th international Congress of Applied Psychology, Melbourne.

Jiménez, P.; Dunk1, A. and Peibl, S. (2015), "Workplace Incivility and Its Effects on Value Congruence, RecoveryStress-State and the Intention to Quit", Psychology, 6, pp. 1930-1939.

Kanwal, F.; Rathore, K. and Qaisar, A. (2019), "Relationship of Benevolent Leadership and Organizational Citizenship Behavior: Interactional Effect of Perceived Organizational Support and Perceived Organizational Politics", Pakistan Journal of Commerce and Social Sciences, 13(2), pp. 283-310.

Ko, S.-H.; Kim, J.; Choi, Y. (2021), “Compassion and Workplace Incivility: Implications for Open Innovation”, 
Journal of Open Innovation, Technology, Market and Complexity, Vol.7 No.95. pp. 1-12. https://doi.org/ 10.3390/joitmc7010095

Lau, W. K. J. (2010), "Empowerment of non-academic personnel in higher education: exploring associations with perceived organizational support for innovation and organizational trust", $P h D$ diss., University of Iowa, available at http://ir.uiowa.edu/etd/843.

Liu, W., Zhou, Z.E. and Che, X.X. (2018), "Effect of Workplace Incivility on OCB Through Burnout: The Moderating Role of Affective Commitment", Journal of Business and Psychology, https://doi.org/10.1007/s10869-018-9591-4.

Maan, A.T.; Abid, G.; Butt, T.H.; Ashfaq, F. and Ahmed, S. (2020),“ Perceived organizational support and job satisfaction: a moderated mediation model of proactive personality and psychological empowerment”, Future Business Journal 6:21, https://doi.org/10.1186/s43093-020-00027-8

Malik, F., Chugtai, S., Iqbal, Z. and Ramzan, M. (2013), "Does Psychological Empowerment Bring About Employee Commitment? Evidence from Telecommunication Sector of Pakistan”, Journal of Business Studies Quarterly, Vol.5 No.1, pp. 14- 21.

Miner, K. N., Settles, I. H., Pratt-Hyatt, J. S., and Brady, C. C. (2012), "Experiencing Incivility in Organizations: The Buffering Effects of Emotional and Organizational Support", Journal of Applied Social Psychology, Vol.42, pp. 340-372.

Naderi, N. and Hoveida, R. (2013), "The relationship between Organizational Citizenship Behavior (OCB) and Human Resources Empowerment (HRE) Case study: University of Isfahan (Iran)", International Journal of Human Resource Studies, Vol.3 No.2, pp. 69- 78.

Nitzsche, M., Ribeiro, L. and Laneiro, T. (2018), "Workplace Incivility among Portuguese Hotel Employees: Is Lack of Respect Burning Them Out?", Journal of Spatial and Organizational Dynamics, Vol.VI No.1, pp. $52-71$.

Ojo, B. Y. and Tamunoipiriala, D.C. (2019), "Organizational predators of workplace deviant behavior in hotel industry", Journal of Tourism Management Research, Vol.6 No.1, pp. 1-18.

Oyeleye, O.; Ann O'Connor, N.; Hanson, B. and Sue Dunn, D. (2013), "Relationship of Workplace Incivility, Stress, and Burnout on Nurses' Turnover Intentions and Psychological Empowerment", The Journal of Nursing Administration, Vol.43 No.10, pp. 536-542.

Potipiroon, W. and Ford, M.T. (2019), "Relational costs of status: Can the relationship between supervisor incivility, perceived support, and follower outcomes be exacerbated?", Journal of Occupational and Organizational Psychology, Vol.92, pp. 873-896.

Rani, R.M.; Abdul Rahman, N.R. and Yusak, N.A.M. (2021), "The Effect of Psychological Empowerment on Employee Performance", International Journal of Innovation, Creativity and Change, Vol.15 No.6, pp. 881899.

Rayan, A. R. M.; Sebaie, A.S.M. and Ahmed, N.A. (2018), “The Mediating Role of Psychological Empowerment in the Relationship between the Empowering Leadership Behavior and Work Engagement: A Study Applied on the Cement Sector in Upper Egypt", International Journal of Business and Management, Vol.13 No.12, pp. 18-30.

Rhoades, L., Eisenberger, R. and Armeli, S. (2001), "Affective commitment to the organization: the contribution of perceived organizational support", Journal of Applied Psychology, Vol.86 No.5, pp. 825- 836.

Rukh, L.; Hassan, Q.; Babar, S. and Iftikhar, A. (2018), "Impact of Perceived organizational support and organizational reward on Thriving at work: Mediating role of civility at workplace", International Journal of Management Excellence, 12 (1), 1688-1633.

Selamat, R.S.; Hendryadi and Irsan, T. (2019), "Workplace incivility, self-efficacy, and turnover intention relationship model: a multi-group analysis", RJOAS, 1(85), 358-368. DOI 10.18551/rjoas.2019-01.44

Sen, C.; Mert, I.S. and A. Mohammed Abubakar, M. (2021), "The nexus among perceived organizational support, organizational justice and cynicism", International Journal of Organizational Analysis, 1934-8835 DOI 10.1108/IJOA-11-2020-2488

Sharma, D.R. and Biswakarma, G. (2020), "Mediating Role of Job Satisfaction in the Relationship Between Organizational Support and Job Performance", European Business and Management, Vol.6 No.4, pp. 84-94.

Shen, Y., Jackson, T., Ding, C., Yuan, D., Zhao, L., Dou, Y. and Zhang, Q. (2013), "Linking perceived organizational support with employee work outcomes in a Chinese context: Organizational identification as a mediator", European Management Journal, available at http://dx.doi.org/10.1016/j.emj.2013.08.004.

Spreitzer, G. M. (1995), "Psychological empowerment in the workplace: Dimensions, measurement, and validation", Academy of Management Journal, Vol.38, No.5, pp. 1442-1465.

Spreitzer, G. M. (2008), "Taking stock: A review of more than twenty years of research on empowerment at work". In C. Cooper and J. Barling (Eds.), 'The handbook of organizational behavior, Thousand Oaks, CA: Sage Publications, pp. 54-73.

Steinberg, J.J. (2012), 'Factors influencing psychological empowerment of nurse aides in nursing homes,' Thesis 
Prepared for the Degree of Master of Arts, University of North Texas,

Sumathi, G.N. (2018), "Perceived organizational support in Indian rural public healthcare sector", International Journal of Mechanical Engineering and Technology, Vol.9 No.7, pp. 885-901.

Thomas, K.W. and Velthouse, B.A. (1990), "Cognitive Elements of Empowerment: An "Interpretive" Model of Intrinsic Task Motivation", The Academy of Management Review Vol.15 No.4, pp. 666-681.

Torkelson, E; Holm, K. and Bäckström, M. (2016), "Workplace Incivility in a Swedish Context, Workplace Incivility in a Swedish Context", Nordic journal of working life studies, Vol.6 No.2, pp. 3-22.

Tran, K.T.; Nguyen, P.; Dang, T.T. and Ton, T.N.B. (2018), "The Impacts of the High-Quality Workplace Relationships on Job Performance: A Perspective on Staff Nurses in Vietnam”, Behavioral Science (Basel), Vol.8 No.12, p. 109.

Ugwu, E.S.; Okafor, C.O.; Onyishi, I.E.; Casimir, A. and Chinedu, E.C. (2018),“ Perceived Organizational Politics, Support and Workplace Incivility of Supervisor as Predictors of Turnover Intention”, Open Journal of Political Science, Vol.8 No.4, pp. 547-560.

Wange, Z.; Liu, C.; Yang, S. and Li., L. (2018), "Employee Fitness Programs: Exploring Relationships between Perceived Organizational Support toward Employee Fitness and Organizational Sustainability Performance", Sustainability, Vol.10, p.1930; doi:10.3390/su10061930

Yilmaz, N. and Toylan, N.V. (2021), "The Relationships Between Psychological Empowerment Organizational Trust and Employee Motivation: An Empirical Research on Hotel Employees in Istanbul", Journal of Tourism and Gastronomy Studies, Vol. 9 No.1, pp. 111-130

Zhang, N.; Xu, D.; Li, J. and Zhenxing Gong, Z. (2021), "Effect of Perceived Organizational Support on Fatigue of Chinese Nurses during the COVID-19 Pandemic: Resilience as a Mediator", International Journal of Mental Health Promotion, DOI: 10.32604/IJMHP.2021.015487

Zia-ud-Din, M.; Arif, A.; Shabbir, M.A. (2017), "The Impact of Workplace Incivility on Employee Absenteeism and Organization Commitment", International Journal of Academic Research in Business and Social Sciences, Vol.7 No.5, pp. 205-221. 